Débora Elman é arquiteta, mestre em Comunicação pela UFRGS (Programa de Pós-Graduação em Comunicação e Informação da Universidade Federal do Rio Grande do Sul); coordenadora da Especialização em Moda, Criatividade e Inovação das Faculdades SENAC de Porto Alegre e do curso de Graduação Tecnológica em Design de Moda da mesma instituição. E-mail: deboraelman@terra.com.br

\title{
A cor como representação: o imaginário verde e amarelo
}

\author{
The color as representation: \\ the green-and-yellow imaginary
}

[resumo] Este artigo trata da representação das cores verde e amarela no quadro imaginário de uma nação que se constrói fortemente por meio do futebol como expressão cultural. Abordando estas cores como elementos derivados dos regimes noturno e diurno da imagem, debate-se a constituição de um sujeito pós-moderno que se reconhece e se afirma, em uma identidade brasileira tribalizada e provisória, por meio do discurso imagético complementar das duas cores nacionais.

\section{palavras-chave}

[abstract] This article approaches the representation of green and yellow colors, in the imaginary field of a nation that constructs itself understanding soccer as a strong cultural expression. We consider these colors as elements of nocturnal and diurnal regimes of image, so we discuss the constitution of a post-modern subject that recognizes and affirms itself in a tribal and provisory Brazilian identity, through the complementary discourse of the green and the yellow colors.

[key words] communication; representation; culture; soccer; green-and-yellow. 
A cor é elemento de alto poder discursivo. No campo da comunicação e das representações, as cores - ou sua ausência - veiculam sentidos ancorados na capacidade cognitiva do homem de perceber e reconhecer valores e sensações. Tais sentidos de caráter universal, que Gilbert Durand (1997) sistematiza a partir dos regimes diurno e noturno ${ }^{1}$ da imagem preconizados por Gaston Bachelard, adquirem particularidades convencionadas segundo a construção histórica de cada cultura - e assim vemos que uma mesma cor carrega sentidos diversos, de acordo com a simbologia arquitetada em diferentes sistemas culturais.

No Brasil, o verde e o amarelo são tradicionalmente percebidos como índices de nacionalismo, circunscrevendo a identidade de um território imaginado que ultrapassa as fronteiras geográficas concretas. Dispõe-se aí uma espécie de costura que atua no campo simbólico, unindo sujeitos dispersos no espaço em torno de um conceito entre tantos outros possiveis - de enraizamento, identificação e compartilhamento (MAFFESOLI, 1996).

Uma das manifestações da tribalização pós-moderna é o esporte, com suas características lúdicas e sua grande capacidade de aglutinação temporária em torno de um desejo primal: vencer o adversário. No caso brasileiro, o futebol tornou-se um campo de expressão especialmente significativa desse desejo, sobretudo pela trajetória das seleções nacionais que conquistaram o título mundial por cinco vezes - a única nação a carregar esta distinção. É exatamente no terreno das distinções que se inscreve esta história particular, e é pela capacidade de agregar o sentido da distinção que o verde e 0 amarelo tomam corpo no mundo cotidiano, como a dizer: "este é o grupo dos vencedores".

As cidades brasileiras, no período da Copa do Mundo, parecem mudar de cor por conta de um movimento cívico surreal, que contagia diferentes classes sociais com uma grande intensidade. 0 marketing, apropriando-se do desejo genuíno dessa comunidade imaginada, esmera-se em inovar em produtos como perfumes, sapatos e acessórios. Relatada pelo jornalismo, a moda carrega a potencialidade desse reconhecimento grupal pelo futebol: "A Copa do Mundo é mais uma oportunidade para reforçar o figurino verde e amarelo, que já é referência nacional e internacional há algumas temporadas" (DEODORO, 2006).

Ser a única seleção que participou das 17 edições da Copa do Mundo e também a única pentacampeã fazem com que a equipe chegue sempre como favorita ao troféu. A Copa, como um grande espaço de espetáculo globalizado, torna-se palco de disputa também das grandes corporações do mundo do consumo ${ }^{2}$, como a indústria de artigos esportivos.

Em tempos de Mundial, o Brasil constrói-se como representação por meio da seleção brasileira e das cores nacionais. Com base na ideia de nação, Hans Ulrich Gumbrecht fornece uma explicação para esse fenômeno, que, ao contrário do que uma análise apressada poderia indicar, não aconteceu apenas no Brasil, mas em todos os paises com tradição neste esporte: 


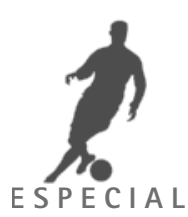

"Acho que na situação globalizada de hoje, a Copa do Mundo de Futebol (...) em todos os paises virou uma situação de identificação com a seleção nacional, quase férias patrióticas. A Copa é um momento suspenso no tempo em que, nostalgicamente, certa identificação forte com as nações volta a emergir"3.

Considerando que a nação é uma matéria amorfa (EAGLETON, 2003) que precisa ser moldada pelo Estado até constituir uma unidade, seus elementos indisciplinados serão assim reconciliados sob uma única soberania. Todavia, uma vez que esse processo é internacional, a nação é também, nesse sentido, elevada a um status global. Assim, 0 "pertencer a tribo" gera a cidadania no mundo.

\section{Futebol e sujeito pós-moderno}

Para o sujeito do lluminismo, que concebia o homem como indivíduo totalmente centrado, unificado, dotado de razão, consciência e ação, a identidade seria o centro essencial do eu, que nasceria e morreria com ele. Uma segunda noção, a de sujeito sociológico, fruto da maior complexidade das sociedades modernas e da consciência de que este não era autônomo e autossuficiente, mas sim "formado da relação com outras pessoas importantes para ele, que mediavam para o sujeito os valores, sujeitos e símbolos - a cultura - dos mundos que ele/ela habitava" (HALL, 2003, p. 11), teria a identidade formada na interação entre o eu e a sociedade, atuando na criação de identidades culturais. Uma terceira concepção de sujeito, o pós-moderno, é desprovida de uma identidade fixa, essencial ou permanente, assumindo, dessa forma, várias identidades de caráter passageiro, algumas vezes transitórias.

Em toda parte, estão emergindo identidades culturais que não são fixas, mas estão suspensas, em transição, entre diferentes posições que retiram seus recursos de diferentes tradições culturais e são o produto desses complicados cruzamentos e misturas cada vez mais comuns num mundo globalizado. (HALL, 2003, p. 88)

0 patriotismo, 0 ativo mais zelosamente preservado pelos Estados-nações modernos, foi transferido às forças do mercado e por elas remodelado para campos como o esporte e suas comemorações. A globalização tirou do Estado o poder ou o desejo de manter uma união sólida e inabalável com a nação, pois, ao transferir a maior parte de suas tarefas intensivas de mão de obra e capital aos mercados globais, os Estados têm muito menos necessidade de um fervor patriótico (BAUMAN, 2005). Daí a demanda pelas ditas "comunidades guarda-roupa", em que qualquer evento espetacular ou escandaloso pode se tornar um pretexto para ativá-la, como um novo inimigo público número um ou a partida de um jogo de futebol: "As comunidades guarda-roupa são reunidas enquanto dura o espetáculo e prontamente desfeitas quando os espectadores apanham seus casacos nos cabides" (BAUMAN, 2005, p. 37).

No futebol, um torcedor não se encontra, ouve ou interage com todos os outros membros da torcida da qual faz parte, nem com os integrantes da equipe, mas os imagina como pertencendo a uma mesma coletividade, uma tribo de torcedores com uma estética própria. Os torcedores fazem parte de uma comunidade - ou nação - mesmo estando sozinhos em frente ao aparelho de TV ou computador e, nesse sentido simbólico de pertencimento, podem usar espontaneamente as cores que os representam como nação numa competição mundial. Na lógica pós-moderna, a emergência dos tribalismos toma o lugar do individualismo, e o que liga uma pessoa a uma ou mais tribos é o sentimento de perten- 
ça, em função de uma ética específica e no quadro de uma rede de comunicação $0^{4}$. Essas tribos se caracterizam por possuir uma temporalidade própria, muitas vezes efêmera, organizada de acordo com as ocasiões que se apresentam.

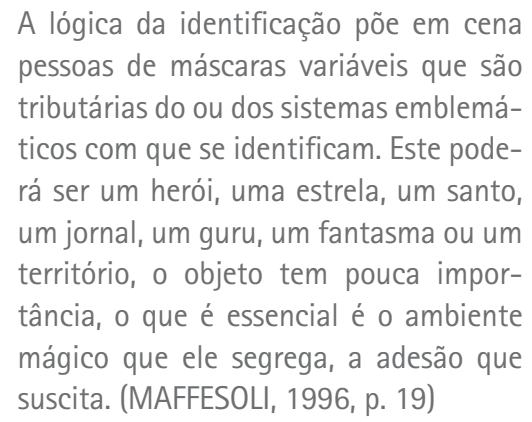

0 ganho do poder, do reconhecimento e da notoriedade é absolutamente presenteísta, obtido pelo ganho imediato de um objetivo em torno do qual o grupo se agrega, tornando um jogo a própria sociedade. "É assim que, num jogo circular sem fim, a ética, o que agrega o grupo, torna-se estética, emoção, comum, e vice-versa" (MAFFESOLI, 1996, p. 19).

Ao contrário do que ocorre no futebol, existe marcante distância do povo brasileiro com os símbolos políticos, partidários ou cívicos. A partir de uma baixa estima pelo Estado, desenvolve-se a dificuldade de associação espontânea positiva com os símbolos nacionais, principalmente com um Estado incapaz de oferecer o que habitualmente se considera sua obrigação evidente, como educação, saúde e segurança. A cultura, nesse caso o futebol, funciona separadamente do sistema político, o que provavelmente explique a facilidade da apropriação das cores verde e amarela como símbolo de Brasil no esporte.

Atualmente, o futebol é um dos esportes mais populares no mundo, apesar da diversidade cultural dos povos e nações. Nos séculos XIX e XX, que se caracterizaram pelo intenso desenvolvimento dos meios de transporte e comunicação, as distâncias entre os mais diversos pontos do planeta foram sendo encurtadas. 0 fortalecimento dos Estados nacionais, em substituição aos antigos impérios continentais e coloniais, provocou a emergência dos sentimentos nacionalistas e o fortalecimento das identidades nacionais, constituindo-se num dos principais traços da modernidade (HALL, 2003). Nesse contexto, o esporte foi usado para forjar traços de identidade em diversas nações: a popularização das competições transformou os espaços de esporte em pequenas reproduções dos campos de batalha, nos quais as vitórias de um individuo ou das equipes passaram a assumir uma nova dimensão, utilizadas politicamente pelos governos nacionalistas para provar a superioridade de uma nação, etnia ou sistema de governo.

Por ser vitorioso, o futebol é um discurso capital sobre a nacionalidade brasileira. Com o futebol se popularizando e com a conquista do primeiro título mundial, em 1958, o Brasil, como nação imaginada, apropria como valor cultural a paixão pelo futebol. Se o Brasil é uma "pátria de chuteiras", de muitos times que vestem camisas multicores, quando é tempo de Copa do Mundo, o Brasil é verde-amarelo. 
0 futebol, como espetáculo, constitui-se pela presença das celebridades. Elas são referenciais para os fãs e levam as pessoas aos eventos. A diferença básica entre as celebridades do esporte e os ídolos de outros universos, como o cinema e o show business, é reveladora:

\begin{abstract}
Enquanto os primeiros [os do esporte] possuem qualidades que os transformam em heróis, os do outro universo raramente possuem estas características. A explicação para este fato reside no aspecto agonistico que permeia o esporte. 0 "sucesso" de um atleta depende do "fracasso" do seu oponente. É uma competição que ocorre na ação do espetáculo. Ambos, ídolos do esporte e ídolos da música, se transformam em celebridades, porém, só os ídolos do esporte costumam ser considerados heróis. (HELAL, 2003, p. 1)
\end{abstract}

Joseph Campbell (2004) esclarece a diferença entre celebridades e heróis. Enquanto os primeiros usam a fama e o sucesso somente para si, os heróis devem atuar no sentido de remissão da sociedade. A saga clássica do herói fala de um ser que parte do mundo cotidiano e se aventura a enfrentar obstáculos intransponiveis, vence-os e retorna para casa.

Terminada a busca do herói, por meio da penetração da fonte, ou por intermédio da graça de alguma personificação masculina ou feminina, o aventureiro deve retornar com seu troféu transmutador da vida. 0 círculo completo, a norma do monomito, requer que o herói inicie agora o trabalho de trazer os símbolos (...) de volta ao reino humano, onde a bênção alcançada pode servir à renovação da comunidade, da nação, do planeta ou dos dez mil mundos. (CAMPBELL, 2004, p. 195)

Essa característica do "ídolo-herói" acaba por transformar o mundo do esporte em um campo fértil para a gestação de mitos e heróis: "Ouvi tantas vezes os jogadores falarem do peso da camisa da Seleção, é como carregar o país para o campo. Quando se junta tudo isso numa estética simples e limpa, você não precisa dizer mais nada, o amarelo já diz tudo, essa cor sempre vai representar o Brasil", diz Sandy Bodecker, vice-presidente responsável pela Sport Culture da Nike internacional, que produz 0 uniforme oficial da seleção brasileira (citado por CAMPOS, 2006, p. 99).

\title{
0 amarelo diurno e o verde noturno
}

A dupla verde e amarela representa o Brasil desde 1822, com a proclamação da Independência do Brasil. D. Pedro I, naquela ocasião, retirou as cores azul e branca que identificavam a Coroa Portuguesa, adotando como cores imperiais brasileiras as que identificavam a sua origem e a da sua esposa: o verde dos Bragança e o amarelo dos Habsburgos. Uma nova bandeira para o Império, criada por Debret, já traz o desenho do retângulo verde e o losango amarelo, origem da bandeira republicana adotada em 1889.

Mesmo as mudanças de regime ou de ideologia nem sempre são acompanhadas por uma transformação na bandeira ou pelo menos uma transformação radical. (...) em 1889, o Brasil republicano não só conservou a cor emblemática verde da casa de Bragança (sendo este verde mais tarde reinterpretado como a cor da floresta amazônica) como continuou a associar-lhe o globo imperial, transformando-o numa esfera armilar, supostamente destinada a recordar os primeiros navegadores portugueses. (PASTOREAU, 1993, p. 37)

Em momentos distintos da história recente podemos analisar o uso da cor como representação no Brasil (GUIMARÃES, 2000). Em 1984 encontramos o Brasil nas ruas, de amarelo, pedindo pelo direito ao voto direto para a Presidência da República. Nas "Diretas Já", o amarelo cumpriu seu papel de símbolo de alerta e como cor de meIhor assimilação mnemônica, apesar de ter sido uma manifestação dita organizada, não espontânea. Em agosto de 1992, em protesto ao pedido do então presidente do 
Brasil, Fernando Collor de Mello, para que as pessoas vestissem as cores do Brasil em apoio ao seu governo, houve uma manifestação coletiva e espontânea da população que foi chamada "Domingo Negro" - o Brasil vestiu-se de preto com bandeiras, fitas, roupas e "caras-pintadas", utilizando a cor na sua dimensão simbólica de luto e pesar.

A cor como comunicação tem merecido maior atenção de profissionais de mídia e de marketing. De acordo com uma pesquisa realizada pelo Ministério do Turismo em 2005, com o objetivo de subsidiar a construção de uma marca para uso em produtos feitos no Brasil, a maioria dos entrevistados declarou que a natureza é o maior motivo para visitar o Brasil (75\% das respostas de 5 mil questionários aplicados em 18 paises), e as referências principais são o sol e as belezas naturais (PORTES, 2006). De acordo com a mesma pesquisa, após a estada, os visitantes agregam, como novo valor, a alegria do povo brasileiro.

Ao tentar analisar a sociedade brasileira nesse aspecto lúdico, além da contribuição africana e indígena, pode-se ter como referência também o baixo nível de disciplina dos corpos que a Igreja Católica e a escola conseguiram impor.

Colabora para a formação dessa sociabilidade lúdica a desvalorização do passado, principal fonte de angústias, remorsos e culpas, assim como a importância dos contatos pessoais, elemento básico para a sobrevivência numa sociedade patrimonialista, gerando o prazer da convivência e a valorização do conhecimento de outras pessoas. Esse é, talvez, o traço cultural que mais chama a atenção dos estrangeiros que visitam ou se estabelecem no país. (SORJ, 2000, p. 35)

Assim, mais do que apenas pertencerem às cores da bandeira nacional, tradicionalmente ensinadas nas escolas como o verde significando as matas e o amarelo, o ouro das riquezas nacionais, o verde e o amarelo podem ter outros significados que expliquem sua escoIha espontânea para representar, e com tanta intensidade, o Brasil do futebol. 0 branco e o azul, por fazerem parte da bandeira brasileira, poderiam ser usados com maior frequência, mas atuam no imaginário da população como coadjuvantes da dupla auriverde.

Os códigos de linguagem são os que guiam o homem na produção e recepção dos textos. A partir dos códigos primários da percepção visual e da decodificação neurônica das cores, adquirimos naturalmente um repertório de signos que, com a atuação reguladora dos códigos secundários, passa a construir o que conhecemos como linguagem das cores. Para a sobrevivência psíquica, o homem constrói sobre a estrutura da primeira realidade sensivel, predeterminada biofisicamente, uma outra realidade, operada pela cultura (BYSTRINA citado por GUIMARÃES, 2000, p. 53). 
Essa "segunda realidade", concebida pela criatividade, imaginação e fantasia humana, tem um caráter sígnico e é essencialmente narrativa. Um texto cultural possui elementos comuns com os antigos textos conhecidos da cultura humana no processo comunicativo da cultura, os mitos e os rituais: "Aquilo que os homens têm em comum se revela nos mitos. (...) Eles ensinam que você pode se voltar para dentro e você começa a captar a mensagem dos símbolos" (CAMPBELL, 1990, p. 5-6). Dessa forma, se, na perspectiva simbólica, para estudar os arquétipos ${ }^{5}$ fundamentais da imaginação humana tomamos os regimes diurnos e noturnos da imagem como agrupamentos de estruturas vizinhas, também em torno dos processos rituais e nos mitos podemos distinguir as constantes universais da cor.

Enquanto as cores, no regime diurno da imagem, se reduzem a algumas raras brancuras azuladas e douradas, preferindo aos cambiantes da paleta a nítida dialética do claro-escuro, sob o regime noturno toda a riqueza do prisma e das pedras preciosas vai se desenvolver. (DURAND, 1997, p. 220)

Os índios brasileiros aplicavam as cores com diversas finalidades de representação de uma segunda realidade, fantástica, mitológica e de comunicação com o mundo espiritual. Usavam as cores como informação, organizando visualmente as faixas etárias, os sexos e o status social. "Os padrões pintados no corpo determinam a diferença da proveniência, investem o usuário de poder sobrenatural, abrem a fenda entre natureza e cultura" (AGUIAR ${ }^{6}$ citado por GUIMARÃES, 2003). No Brasil indígena, a natureza generosa com o cromatismo natural impõe uma necessidade de superação cromática para alcançar o sobrenatural, caracteristica que será determinante na identidade cromática brasileira até hoje.

Os africanos trouxeram novas concepções de religiosidade e arte, um universo mágico e a comunicação com os espíritos e divindades da segunda realidade, convidados em rituais para nossa primeira realidade (PRANDI ${ }^{7}$ citado por GUIMARÃES, 2003). As cores africanas apresentam uma simbologia menos metafísica e muito mais estruturada (passivel de narração), como as que identificam quatro importantes orixás, cada um com suas personalidades e características espirituais próprias, assim como a materialidade, o gosto por sons, comidas e cores.

Através do sincretismo religioso, étnico e cultural no uso das cores no Brasil, podemos relacionar o não uso das cores azul e branca como identitárias do brasileiro no futebol, pela associação destas cores com outros eventos igualmente importantes no imaginário nacional fora do campo das representações do esporte. 0 branco é a cor da pureza, da castidade, das vestes de batismo, da brancura do cordeiro, das virgens, das vestais, a neutralidade, a ideia de paz e renúncia (PASTOREAU, 1993, p. 42-43). A cor branca, para o Brasil, é associada ao réveillon (receber o novo ano com roupas brancas, o grau zero da cor, em oposição ao preto) e aos ritos de purificação afro-brasileiros como o candomblé.

Ligada à luz celestial, a cor branca se liga a rituais de purificação, em "lugares de brancura", o nirvana visual que os poetas assimilam quer ao éter, ao ar puríssimo, quer, no caso de Goethe, ao Urphanomen, quer, no caso de Claudel, ao vestido da "purissima". A psicologia contemporânea confirma, de resto, esse caráter privilegiado do azul celeste, do azul pálido. No Rorschach o azul é a cor que provoca menos choques emocionais (...) e as cores frias, entre as quais o azul, agem num sentido de afastamento da excitação. (DURAND, 1997, p. 147-148)

0 azul reuniria, portanto, condições para o repouso e recolhimento. Efetivamente a cor azul, na cultura ocidental (PASTOREAU, 1993), é a cor da fidelidade, da fé, cor da Virgem Maria, cor do céu, do infinito, das origens nobres, do "sangue azul". 0 azul, para o Brasil, é o do manto de Nossa Senhora Aparecida, santa padroeira brasileira.

A camiseta "canarinho" amarelo-ouro foi associada, desde o primeiro campeonato mundial conquistado pelo Brasil, ao feito heroico de um pais - a despeito do significado encontrado em outras culturas, em que o amarelo "é a cor dos traidores, dos cavaleiros desleais, dos falsos moedeiros (no século XIV as suas casas eram pintadas de amarelo), 
cor dos fura-greves, dos trabalhadores que atraiçoaram em favor do patronato, cor dos maridos enganados" (PASTOUREAU, 1993, p. 19-20). Para a heráldica, a ciência dos brasões, o amarelo é a cor da inveja, da inconstância, do adultério e da traição.

Em nossa recente sociedade, sem a tradição da heráldica e distante de fatos históricos como a Inquisição, que usou o amarelo como a cor dos infiéis, e dos usos que fez o nazismo da estrela amarela, o amarelo do Brasil estaria mais próximo da ideia de alegria, de energia, do sol, das praias, da juventude bronzeada e dos nossos heroicos craques "de ouro".

No Oriente, a cor amarela é uma espécie de mediadora entre deuses e homens. Como sua essência é divina, torna-se um atributo de poder para reis, príncipes e imperadores para proclamarem a origem divina do seu poder, trazendo associações entre o ouro, o trigo e os cereais como símbolo de riqueza na Antiguidade. 0 amarelo é a cor da eternidade, assim como o ouro é o metal da eternidade: "Na simbologia alquímica, passa-se constantemente da meditação da substância ouro ao seu reflexo, possuindo o ouro graças ao seu brilho 'as virtudes dilatadas do sol no seu corpo' e tornando-se 0 sol por isso, muito naturalmente o signo alquímico do ouro" (DURAND, 1997, p. 149).

Ao simbolismo do sol liga-se, por fim, o da coroa-solar, o rei-sol, a tendência de se tornar raio ou gládio e a ascensão luminosa para espezinhar um adversário vencido. "Já começa a se desenhar em filigrana, sob os símbolos ascensionais ou espetaculares, a figura heróica do lutador erguido contra as trevas ou contra o abismo" (DURAND, 1997, p. 159).

Ao regime heroico diurno, solar, sucede-se o noturno, lunar, e as águas e a agricultura regidas por ela. A árvore (a mata) adquire um valor simbólico de transcendência.

\begin{abstract}
É essa a implicação nova que sujeita o destino da árvore ao homem. Tal como o homem é animal vertical, não é a árvore vertical por excelência? Os mais velhos carvalhos têm nomes próprios, como os homens. Assim o arquétipo temporal da árvore, embora conservando os atributos da ciclicidade vegetal e da ritmologia lunar e técnica, do mesmo modo como as infra-estruturas sexuais desta última, é dominado pelo simbolismo do progresso no tempo graças às imagens teleológicas da flor, do cimo, e desse filho por excelência que é o fogo. (...) É por esses motivos que na imaginação qualquer árvore é irrevogavelmente genealógica, indicativa de um sentido único do tempo e da história que se tornará cada vez mais difícil inverter. É assim que o pau com rebentos do jogo do Tarô confina com o cetro na simbólica universal e se confunde facilmente com os arquétipos ascensionais e da soberania. (DURAND, 1997, p. 344-345)
\end{abstract}

Guimarães (2000) conta uma história curiosa acontecida na ponte Blackfriars, pintada de vermelho-ferrugem em Londres, onde aconteciam muitos suicídios. $\mathrm{Na}$ década de 1980, ao pintarem a ponte de verde, cor da esperança, o número de suicídios diminuiu em 75\%. Alguns autores citam o prado verde dos duelos, do tecido verde da mesa de roleta e do bilhar, da madeira verde do tênis de mesa, dos gramados das partidas de futebol como os lugares onde se encontram o destino, a esperança e a fortuna. Pastoureau (1993, p. 73) afirma que desde meados do século XII o verde é a cor do jogo e do esporte: "0 laço cultural que, ao longo dos séculos, ligou o verde dos jogos de azar ou de sociedade parece-me incontestável. (...) 0 destino joga-se no campo de honra".

0 espaço marcado por quatro lados se chama campo, que adquire um significado central para a autoafirmação humana no campo da lavoura, campo de batalha, campo de jogo. Sempre se trata de manifestar e afirmar a presença neste espaço limitado em frente a outros. 0 verde também é a cor da permissão, da liberdade, do deixar passar, explicada como oposta e complementar ao vermelho, que sempre foi a cor da proibição e do perigo (GUIMARÃES, 2000). Confirmam-se as relações culturais do verde com a agricultura, a "espera" das primeiras folhas depois do inverno, a simbologia da esperança, da juventude e do novo, o broto. Confirma-se a ligação do Brasil com 
a natureza, mas também o Brasil como celeiro de craques, de campos de onde brotam meninos e suas bolas, alegres e esperançosos.

\section{Considerações finais}

A associação do verde e do amarelo forma um conjunto de imagens ancoradas nos regimes diurno e noturno da imaginação, criando simbologias caracterizadas pela unicidade e complementaridade: o amarelo representando o sol, a luz, o princípio do vigor masculino, e o verde como sombra, agricultura, o princípio da regeneração feminina. As duas cores juntas, força e juventude, simbolizam a energia vital que a afirma-

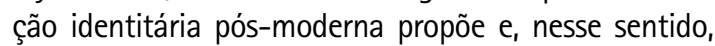
representa a torcida brasileira como nação: alegria, divertimento, coquetel de imagens (LIPOVETSKY, 1989), sedução frívola que suspende o real e o racional, provocando o riso ou surpreendendo com sua criatividade e estetização do cotidiano - leveza apropriada do espírito do tempo que aprecia o lazer, as férias, a sensação e vibração do mundo:
As reuniões festivas e as manifestações emocionais intensas de massa, facilmen- te observáveis hoje, refletem a ascensão do complexo mídia-individualismo e são a expressão coletiva de uma cultura que sacraliza o governo de si mesma, a expe- riência intima, os prazeres do presente. Longe de ser, como alguns afirmam, um tanto precipitadamente, um signo do es- gotamento do individualismo, reproduzem suas características numa escala de massa. (LIPOVETSKY, 2004, p. 81)

No campo da comunicação, impõe-se a pertinência de compreender a subjetividade que ordena nosso conhecimento do mundo, com base na percepção do poder das cores e do que elas representam como veículos portadores de reconhecimento social. 0 Brasil, construído como nação para além - e na verdade anteriormente - dos símbolos concretos da política, sustenta-se como sociedade também por meio dos códigos fluidos e abstratos dos discursos icônicos que distinguem, agregam e fazem pertencer. 0 futebol, sobretudo quando motivado por um evento midiático como a Copa do Mundo, atualiza o conhecimento dos sujeitos sobre uma comunidade imaginada, possibilitando a criação de um campo discursivo no qual os sujeitos pós-modernos se reconhecem. 


\section{NOTAS}

[1] De forma sintética, segundo Durand o homem cria imagens por meio das quais possa superar a morte e o tempo, que a simboliza. Durand (1997) estrutura as imagens em dois regimes. 0 regime diurno reúne as imagens que dividem o mundo em opostos, as imagens que seccionam, separam e distinguem; neste regime, a resolução da morte e da passagem do tempo se dá simbolicamente pelo herói que enfrenta 0 inimigo. 0 regime noturno reúne as imagens que unem os opostos e conciliam; neste regime, há dois tipos de simbolização possiveis: ou o homem cria um universo harmonioso no qual possa viver e conviver com a angústia da morte, ou estabelece uma visão cíclica do tempo em que toda morte significa, ao mesmo tempo, renascimento.

[2] No espaço publicitário urbano, marcas globais declararam que torciam pelo Brasil em garrafas, outdoors e até na réplica de uma mala onde se lia "essa mala torce pelo Brasil" e que passeava pela esteira dos principais aeroportos do Brasil em junho de 2006, como ação publicitária de uma grande indústria de refrigerante. Os jornais e revistas mostraram materias e imagens de uma nação envolvida com o esporte dito nacional. 0 jornal Folha de S.Paulo de 16 de junho de 2006 trazia, em matéria de capa, a passeata dos fiéis evangélicos em comemoração ao dia de Corpus Christi na Avenida Paulista, ressaltando o uso do verde e amarelo nas roupas e nos adereços dos participantes (BRITO, 2006). Em relação a essa mesma comemoração religiosa, as decoracões tradicionais da data, como os desenhos feitos de serragem, traziam essas cores como predominantes (PRATES, 2006).

\section{[3] POR UMA estética do futebol. Zero Hora, Porto Alegre, 8 jul. 2006. Caderno Cultura, p. 2.}

[4] Como exemplo da efêmera identificação do brasileiro com as cores nacionais, observa-se, nas reportagens de antes e depois da Copa do Mundo de 2006, discursos diversos. Em 28 de maio de 2006, a menos de quinze dias do início da Copa, o Caderno Donna de Zero Hora colocava a torcida em campo: "se a seleção está prometendo arrasar, a torcida não pode deixar por menos" (DEODORO, 2006, p. 10). No mesmo caderno, em 30 de julho, passadas três semanas da final da Copa do Mundo que deu à Itália o tetracampeonato, a matéria de moda sugere: "Uma das combinações mais harmônicas do verde é com o amarelo. Só não deu o hexa. Porém para não parecer símbolo nacional ambulante modifique os tons, mas permaneça na combinação. Verde esmeralda com amarelo claro ou musgo com mostarda, por exemplo, combinam as duas cores sem dar tanta bandeira" (GONÇALVES, 2006, p. 17).

[5] Os arquétipos são a zona matricial da ideia, são imagens primordiais, de caráter sempre coletivo. Carl Jung compara os arquétipos aos cristais, cuja estrutura é sempre a mesma, mas cuja forma concreta é variável. "0 mesmo [que com os cristais] se dá com o arquétipo: a princípio ele pode receber um nome e possui um núcleo de significação invariável, o qual determina sua aparência, apenas a princípio, mas nunca concretamente. 0 modo pelo qual, por exemplo, o arquétipo da mãe sempre aparece empiricamente, nunca pode ser deduzido só dele mesmo, mas depende de outros fatores" (JUNG, 2003, p. 91) . 0 símbolo, na sistematização da arquetipologia do imaginário proposta por Durand (1997), é sempre a ilustração concreta de uma imagem arquetípica.

[6] AGUIAR, Nelson. Artes indígenas: Mostra do Descobrimento Brasil+500. São Paulo: Fundação Bienal, 2000.

[7] PRANDI, Reginaldo. Mitologia dos orixás. São Paulo: Companhia das Letras, 2001, p. 32. 


\section{REFERÊNCIAS}

BAUMAN, Zygmunt. Identidade: entrevista a Benedetto Vecchi. Rio de Janeiro: Jorge Zahar, 2005.

BRITO, Fernanda. Marcha para Jesus reúne multidão verde-e-amarela. Folha de S.Paulo, São Paulo, 16 jun. 2006. Caderno Cotidiano, p. C1.

CAMPBELL, Joseph. 0 poder do mito. São Paulo: Palas Atena, 1990.

0 herói de mil faces. São Paulo: Pensamento/Cultrix, 2004

CAMPOS, Cleiton. A beleza do jogo. Revista Simples, São Paulo, jul.-ago. 2006, p. 99

DEODORO, Paola. A torcida entra em campo. Zero Hora, Porto Alegre, 28 maio 2006. Caderno Donna, p. 10.

DURAND, Gilbert. As estruturas antropológicas do imaginário. São Paulo: Martins Fontes, 1997.

EAGLETON, Terry. A idéia de cultura. São Paulo: Unesp, 2003.

GONÇALVES, Xico. Como usar o verde. Zero Hora, Porto Alegre, 30 jul. 2006. Caderno Donna, p. 17.

GUIMARÃES, Luciano. A cor como informação: a construção biofísica, lingüística e cultural da simbologia das cores. São Paulo: Annablume, 2000.

Contrastes de cores e culturas. Revista Gherebh, 2003. Disponivel em: <http://www.cisc.

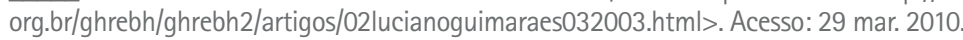

HALL, Stuart. A identidade cultural na pós-modernidade. Rio de Janeiro: DP\&A, 2003.

HELAL, Ronaldo. Mídia e esporte, a construção de narrativas de idolatria no futebol brasileiro. In: XXVI CONGRESSO BRASILEIRO DE CIÊNCIAS DA COMUNICAÇÃO, Belo Horizonte, 2003. Anais do Congresso Brasileiro de Ciências da Comunicação. Belo Horizonte: Intercom, 2003.

JUNG, Carl Gustav. Os arquétipos e o inconsciente coletivo. Petrópolis: Vozes, 2003.

LIPOVETSKY, Gilles. 0 império do efêmero: a moda e seu destino nas sociedades modernas. São Paulo: Companhia das Letras, 1989.

Metamorfoses da cultura liberal. Porto Alegre: Sulina, 2004.

MAFFESOLI, Michel. No fundo das aparências. Petrópolis: Vozes, 1996.

PASTOUREAU, Michel. Dicionário das cores do nosso tempo: simbólica e sociedade. Lisboa:

Stampa, 1993.

PORTES, Ivone. Governo cria marca para promover produtos e serviços do Brasil no exterior. Folha Online, 17 fev. 2005. Disponivel em: <www1.folha.uol/folha/dinheiro/ult91u93511.shtml>. Acesso em: 20 jul. 2006.

PRATES, Tharsila. Corpus Christi é celebrado com tapetes coloridos em cidades de SP. Folha de S.Paulo, São Paulo, 16 jun. 2006. Caderno Cotidiano, p. C1.

SORJ, Bernardo. Nova sociologia brasileira. Rio de Janeiro: Jorge Zahar, 2000. 